last year when it was revealed more than one in four (27\%) of five-year-old children suffered from visible tooth decay, a fall from the previous figure of three in ten $(31 \%)$ in 2008.

Chief Executive of the British Dental Health Foundation, Dr Nigel Carter OBE, welcomed the first survey of its kind, and encouraged parents and education workers to take on vital oral health information: 'It is the first time we have seen the progress of oral health development from birth through to starting school, and the overall results are encouraging. Almost nine in ten three-year-olds are getting the right oral health routine at a crucial age of their development. Diet is a constant theme when discussing health issues in the UK, and the results suggest parents understand that dried fruit and fruit juices are not good for their baby's oral health.

'The stark regional inequalities are a cause for concern. They highlight a clear need for water fluoridation to help tackle these differences, particularly in the more deprived areas of the country. The addition of fluoride in toothpaste alone has been responsible for reducing decay by up to $50 \%$. Levels of dental decay have fallen in both fluoridated and non-fluoridated areas in the UK with the greatest reductions seen in fluoridated areas, yet only $12 \%$ of the population have fluoridated water'.

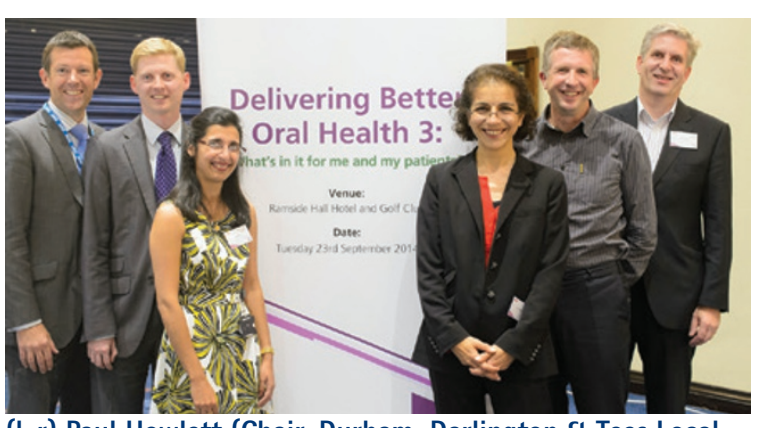

(I-r) Paul Howlett (Chair, Durham, Darlington \& Tees Local Dental Network), Dr Richard Holmes (Newcastle University), Kamini Shah (Consultant in Dental Public Health), Anousheh Alavi (Scientific Affairs Manager, Colgate UK), Professor Jimmy Steele (Newcastle University), Cameron Ward (Director, Durham, Darlington and Tees Local Area Team)

\section{$\mathrm{DBOH}$}

Delivering better oral health: an evidence-based toolkit for prevention, was published on 12 June 2014 by Public Health England and last updated on 24 September 2014.

This latest edition of the guidance provides evidencebased interventions and new advice on how dental health professionals can improve and maintain the oral and general health of their patients. It includes advice on the use of fluoride; brushing your teeth; how to prevent gum disease; tooth erosion; eating a healthy balanced diet; stopping tobacco use; and drinking within the lower risk alcohol guidelines.

To see the full guidance, go to the following link: https://www.gov.uk/government/publications/delivering-better-oral-health-an-evidence-based-toolkit-forprevention\#history.

\title{
VOLUNTEERS NEEDED THIS CHRISTMAS
}

National homeless charity Crisis is making its annual call on dental professionals to provide treatment for homeless people at its temporary centres this Christmas.

Crisis at Christmas 2014 runs from 23-30 December, with centres set to open across London, Newcastle and Edinburgh. As well as warmth, companionship and hot meals, guests will also receive healthcare and specialist advice on housing, work and benefits.

The dental service relies on qualified volunteer dentists, dental nurses and dental hygienists

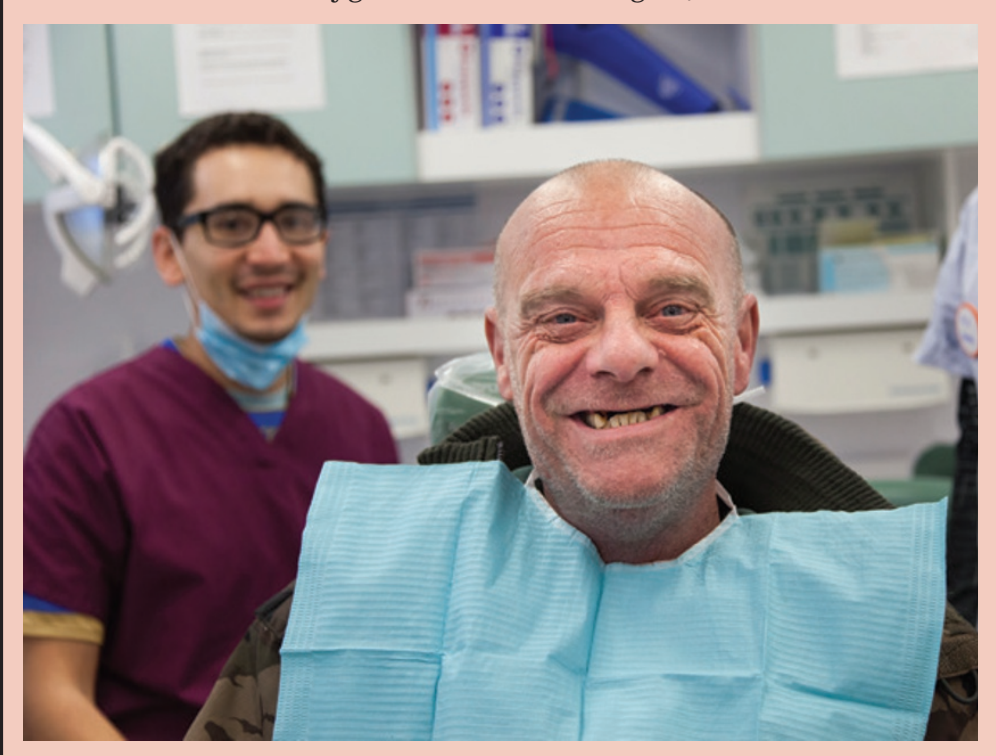

\section{CONSULTATION OPENS ON FTP CASE EXAMINERS}

The Department of Health (DH) has launched a consultation on a Section 60 Order that would allow the General Dental Council (GDC) to introduce case examiners.

Earlier this year the DH recognised the need for urgent change to allow the GDC to streamline its fitness to practise processes and it would now like your views.

By means of this Order the GDC will be able to amend its current legislation (The Dentists Act 1984) allowing it to introduce:

- Case examiners to replace the Investigating Committee which will reduce the amount of time taken to make a decision

- Provide the registrar with powers to review decisions to close cases and to refer cases to the Interim Orders Committee at any point in the process

- Provide a right to registrants to to provide a range of routine dental treatments including check-ups, scaling, polishing and fillings. In 2013, 404 dental consultations took place with 304 guests receiving treatment across all centres. Two hundred and seventy guests were directed to where they could get NHS dental treatment in London during the rest of the year.

Crisis at Christmas centres are run by thousands of volunteers from all walks of life. Registration is open at www. crisis.org.uk/volunteer.

\section{review the decision to issue a warning against them}

- Allow the GDC - in specified circumstances - to agree with a registrant limitations on their practice in order to address any issues which have been raised (known as undertakings).

The advantages of introducing case examiners would be an increase in the speed and agility with which decisions could be made - improving the process for both the registrants and patients involved; it would enable the GDC to use its resources more efficiently as well as bringing an improvement in the consistency of decision making.

Have your say in the consultation by following this link: https://www. gov.uk/government/consultations/ measures-to-improve-the-gdcsprocesses-on-fitness-to-practice. 